\title{
KEBIJAKAN REDAKSIONAL DALAM KONVERGENSI MEDIA (Studi Kasus Jawa Pos)
}

\author{
Irawan Wibisono, Pawito, Ismi Dwi Astuti \\ Universitas Sebelas Maret Surakarta
}

\begin{abstract}
ABSTRAK
Kedatangan teknologi digital menurut beberapa ahli akan membunuh koran secara perlahan. Bahkan pelaku industri media sendiri turut mengamini prediksi yang begitu logis tersebut. Konvergensi media adalah sebuah keniscayaan yang mutlak perlu diantisipasi para penerbit media cetak melalui peningkatan sumber daya manusia perusahaan pers dalam penguasaan informasi dan teknologi. Jawa Pos menjadi salah satu koran nasional di Indonesia yang telah melakukan konvergensi. Penelitian ini bertujuan untuk mendiskripsikan bagaimana kebijakan redaksional Jawa Pos dalam menghadapi konvergensi media. Penelitian ini menggunakan pendekatan kualitatif dengan model penelitian studi kasus. Penelitian kualitatif ini diharapkan mampu memberikan gambaran yang detail dan mendalam tentang dimensi atau level konvergensi Jawa Pos. Pengumpulan data dilakukan dengan cara wawancara mendalam terhadap pemimpin umum Jawa Pos, redaktur pelaksana, redaktur, dan wartawan. Hasil penelitian ini menunjukkan Jawa Pos telah memiliki kebijakan redaksional yang memenuhi seluruh aspek dalam konvergensi media. Antara lain melakukan ekspansi perusahaan, promosi silang, dan menciptakan sumber daya manusia serba bisa.
\end{abstract}

Kata Kunci: Konvergensi Media, Kebijakan Redaksi, Perusahaan Pers. 


\section{Pendahuluan}

Surat kabar atau koran merupakan salah satu dari The "Big Five" Traditional Media (Straubhaar, 2009). Selain koran, media tradisional yang termasuk lima besar adalah majalah, radio, televisi dan iklan atau media luar ruang. Kelimanya dikatakan merajai media tradisional lantaran cakupan audiens yang terbesar. Salah satu ciri media tradisional adalah masih menggunakan teknologi analog yang dewasa ini mulai tersaingi dengan keberadaan media baru sebagai dampak lahirnya teknologi digital.

Kedatangan teknologi digital menurut beberapa ahli akan membunuh koran secara perlahan. Bahkan pelaku industri media sendiri turut mengamini prediksi yang begitu logis tersebut. Philip Meyer, penulis buku Vanishing Newspaper memprediksi pada kuartal pertama tahun 2043 sudah tidak ada lagi koran di Amerika. Menurutnya, media cetak akan banyak ditinggalkan kecuali di negara-negara yang perkembangan teknologi informasi berjalan lambat serta masyarakat masih mengandalkan informasi dari koran cetak. Ia meyakini, pembaca koran terakhir akan menghilang pada September 2043. Hal yang sama dikatakan Chairman dan CEO News Corp Rupert Murdoch. Pada tahun 2000, ia meramalkan media cetak akan mati dalam 20 tahun kedepan. (Supadiyanto, 2013).

Perlahan namun pasti seluruh prediksi itu mulai terbukti. Lembaga pengamat media di Amerika, Paper Cuts, mengumumkan adanya penurunan oplah koran. Dampaknya, sejak 2008 hingga 2013 lebih dari 166 surat kabar di negeri Paman Sam itu tutup. Tak hanya di Amerika, di dunia internasional pun fenomena penurunan oplah koran juga terlihat. Di Jepang, oplah koran pada tahun 2000 sebanyak 53,7 juta eksemplar, namun pada tahun 2011 turun menjadi 48,3 juta eksemplar. (Antaranews.com, 2013). Bahkan majalah paling populer yang berumur 85 tahun, Newsweek resmi berhenti 
cetak pada akhir tahun 2012 dan berganti wajah menjadi media digital per Januari 2013. Surat kabar tertua di Amerika itu mengakui sudah tidak sanggup membendung peralihan tren media cetak ke elektronik. Departemen Sirkulasi Newsweek mengatakan pada tahun 2000 oplah koran mencapai 3.134.046 eksemplar. Sedangkan pada tahun 2012, penjualan mereka terjun bebas menjadi 1.527.157 eksemplar. (Batampos.co.id, 2013).

Namun apa yang menggejala di Amerika belum dirasakan di dataran Asia. Surat kabar di Asia dapat dikatakan masih dapat berdiri tegak ditengah gempuran teknologi informasi yang kian pesat. Bahkan sejumlah koran mengalami pertumbuhan meskipun tidak signifikan. Hasil survey yang dilakukan World Association of Newspapers and News Publisher (WAN-IFRA) menunjukkan bahwa koran masih lebih unggul daripada internet. Dalam forum World Newspaper Congress dan World Editors Forum di Wina, Austria 13 Oktober 2011, CEO WAN-IFRA Christoph Riess (2011) menegaskan bahwa kebesaran surat kabar masih terbukti.

Secara intens WAN-IFRA memonitor perkembangan surat kabar di penjuru dunia. Hal itu dilakukan sejak tahun 1988 dengan lebih dari 200 negara menjadi sasarannya. Di tahun 2011, survey difokuskan pada 69 negara yang dianggap mewakili 90 persen nilai industri global, dalam sirkulasi dan perolehan iklan. Hasilnya adalah koran masih menjangkau pembaca 20 persen lebih banyak setiap harinya dibandingkan dengan internet. Jika diprosentase, koran menjangkau secara total 2,3 miliar orang sedangkan internet hanya menjangkau 1,9 miliar orang. (Riess, 2011).

Ketahanan media di Asia juga disampaikan dalam Kongres tahun 2012 di Bali. Presiden WAN-IFRA Jacob Mathew mengatakan koran dianggap masih menjadi andalan bagi pelaku usaha media Asia dalam memperoleh pendapatan serta peningkatan jumlah pelanggan. (Balipost.com, 2012). Di tahun 2014 di forum yang sama WAN-IFRA merilis oplah surat kabar dunia masih bisa tumbuh 2 persen. (Jawapos.com, 2014). 
Meski begitu penerbit surat kabar tetap harus berjaga-jaga dengan perkembangan teknologi yang kian menggila. Sebab, ancaman utama surat kabar kedepan masih tetap sama yakni bergesernya pembaca setia surat kabar ke media baru atau media online. Sebenarnya kedua jenis media itu memiliki kelebihan dan kekurangan masing-masing. Surat kabar memiliki keunggulan penyampaian isi berita yang mendalam dan bisa diarsipkan. Namun media analog ini terkesan lambat karena informasi yang menarik pada hari ini baru dapat dinikmati pembaca keesokan harinya. Sementara media online memiliki keunggulan yaitu kecepatan penyampaian berita namun lemah dalam akurasinya. (WAN-IFRA, 2009).

Jika perusahaan surat kabar ingin bertahan dalam menghadapi ancaman media online semestinya tidak tinggal diam. Karena perkembangan teknologi tidak membutuhkan waktu yang lama untuk melahirkan inovasi baru. Hanya dalam hitungan detik, teknologi dapat menciptakan media baru dengan segala variannya. Hal ini direspon baik oleh perusahaan media yang tergabung dalam Serikat Perusahaan Pers (SPS) dalam Kongres XXVII di Jakarta tahun 2007. Dalam kongres tersebut menghasilkan sejumlah rekomendasi antara lain konvergensi media adalah sebuah keniscayaan yang mutlak perlu diantisipasi para penerbit media cetak melalui peningkatan sumber daya manusia perusahaan pers dalam penguasaan informasi dan teknologi. (Kompas, 2011).

Briggs dan Bourke (dalam Dwyer, 2010) mengatakan pada awalnya istilah "konvergensi" diaplikasikan pada perkembangan teknologi digital yang paling sering terjadi, yaitu integrasi teks, angka, gambar, dan suara-atau digitalisasi. Meskipun demikian, hal itu hanyalah bagian kecil dari perubahan pengelolaan media saat ini. Keberadaan internet telah merubah pola produksi, distribusi dan konsumsi konten. Konvergensi juga diartikan sebagai integrasi horisontal dari perusahaan media melalui lintas distribusi saluran seperti melalui radio, cetak, atau televisi. Namun sekarang 
konvergensi harus dilihat dengan cara yang lebih luas. Konvergensi dimaksudkan sebagai suatu penyatuan langkah perusahaan yang didalamnya terjadi serangkaian diskontinyuitas di bidang teknologi, infrastruktur, perilaku konsumen, dinamika kompetensi, yang terus menerus berhadapan dengan kompetitor baru, perubahan model bisnis, penemuan baru seputar bisnis media, telekomunikasi, dan teknologi. (Rose, 2007).

Konvergensi media bukanlah semata internetisasi dan digitalisasi, melainkan ada implikasi pada newsroom. Yakni pengelolaan berbagai konten berita ke dalam ruang berita yang sama, yang kemudian didistribusikan ke berbagai kanal yang ada, misalnya koran, radio, televisi, media online, dan media lain yang disesuaiakan dengan segmen tertentu. (Krotz, 2008). Salah satu yang mendasar dalam konvergensi media adalah adanya empat fase konfergensi media, yakni proses produksi terintegrasi (integrated production), Sumber Daya Manusia (SDM) profesional yang mempunyai sejumlah keahlian (multiskilled professional), pola pengiriman yang beragam (multiplatform delivery), dan audiens yang aktif (active audience). (Domingo, 2007).

Domingo (2007) juga menyebut bahwa kovergensi media menuntut pekerjaan profesional yang multiskilled atau bukan hanya menguasai satu jenis keahlian. Konvergensi menuntut perubahan kualitas SDM media, dalam hal ini reporter dan redaktur, dari hanya menguasai satu keahlian menjadi menguasai berbagai keahlian. Jika semula reporter hanya bertugas membuat berita tulis, kini reporter diharuskan membuat berita video atau berita audio. Jika sebelumnya redaktur hanya bertugas menyunting berita tulis, kini juga dituntut mampu mengedit berita dengan format online, video, dan lain sebagainya.

Praktik konvergensi media sudah dilakukan beberapa perusahaan media. Di luar negeri, Rupert Murdoch, pemilik perusahaan News Corp telah banyak melakukan merger dan akuisisi ranah produksi hulu-hilir maupun distribusi yang terpampang oleh $20^{\text {th }}$ 
Century Fox, FOX News, STAR TV dan The Walt Disney Company. Di dalam negeri, ada beberapa media nasional yang telah menerapkan konvergensi media. Grup Tempo melakukan konvergensi media dengan menyediakan versi online dalam bentuk tempo.co dan membuat e-paper. Sehingga Tempo memiliki format cetak baik koran maupun majalah dan hadir dalam bentuk online. Contoh lainnya adalah grup Kompas Gramedia. Kompas tetap bertahan dengan identitasnya sebagai koran cetak yang lahir sejak tahun 1965. Tahun 2008 Kompas membentuk Kompas Cyber Media yang memegang edisi online yaitu kompas.com dan Kompas Jaringan. Konvergensi semakin terlihat pada tahun 2011 saat Kompas mendirikan Kompas TV dan menerbitkan e-paper.

Selain kedua media tersebut, perusahaan koran yang cukup responsif melakukan konvergensi adalah Jawa Pos. Bahkan jauh sebelum meledaknya pemanfaatan internet sebagai wadah bagi media online, Jawa Pos sudah muncul dengan Jawa Pos News Network (JPNN) pada tahun 1987. Kala itu Jawa Pos memiliki lebih dari 80 surat kabar, tabloid dan majalah di seluruh Indonesia. Setelah sukses mengembangkan media cetak, kesadaran untuk melakukan konvergensi lebih nampak lagi. Jawa Pos mengaktifkan situs berita resmi jpnn.com yang kini menjadi jawapos.com. Selain itu dikembangkan pula koran versi digital hingga mendirikan stasiun televisi Jawa Pos TV pada tahun 2015. Perkembangan bisnis media Jawa Pos diakui pelaku usaha koran di dunia. Terbukti pada tahun 2011, WAN-IFRA memberikan penghargaan Newspaper of the Year2011dalam ajang tahunan World Young Reader Prize. Tak cukup itu, Jawa Pos juga menyandang gold medal dalam Asian Media Awards selama dua tahun berturut-turut yaitu 2012 dan 2013. Pada tahun 2014 di ajang yang sama Jawa Pos menyabet silver medal. (jawapos.com, 2016).

Pelaksanaan konvergensi media sebagaimana yang dilakukan Jawa Pos memang tidak semudah membalik telapak tangan. Hal ini menyangkut tuntutan merubah 
kebiasaan yang selama berkarir dilakukan di jajaran redaksi. Sebagian besar awak redaksi sudah terbiasa dengan kebijakan redaksional media cetak yang terpola untuk meliput, menyunting dan menerbitkan berita untuk edisi esok hari. Sementara media online atau media digital harus tayang secepat mungkin. Sebenarnya proses jurnalistik termasuk peliputan dan produksi berita masih sama, hanya caranya saja yang berbeda. Cara tersebut menjadi tren baru dalam perkembangan teknologi dan media baru. (Straubhaar \& LaRose, 2008).

Dengan adanya perubahan sistem kerja tersebut, kebijakan redaksional menjadi kunci. Kebijakan redaksional adalah sikap "politik" media dalam memandang suatu permasalahan juga aturan keredaksian dan kewartawanan yang diterapkan (Abdullah, 1995). Kebijakan redaksional merupakan ketentuan yang disepakati oleh redaksi media massa tentang kriteria berita atau tulisan yang boleh dan tidak boleh dimuat atau disiarkan, juga kata, istilah, atau ungkapan yang tidak boleh dan boleh dipublikasikan, sesuai dengan visi dan misi media. Kebijakan tersebut menjadi tanggungjawab penuh pemimpin redaksi. Dimana tugas utamanya sebagai orang yang mengendalikan keredaksian di perusahaan yang meliputi penyajian berita, penentuan liputan, pencarian fokus pemberitaan, pemilihan berita, berita pembuka halaman (opening news), menugaskan atau membuat sendiri tajuk dan sebagainya. (Djuroto, 2005). Hingga kini belum ditemukan penelitian yang mengulik bagaimana sebuah kebijakan redaksi dilakukan dalam konvergensi media.

Berdasarkan uraian sebelumnya, konvergensi media adalah cara media untuk beradaptasi dengan lingkungan eksternal yang terus berkembang, terutama karena pengaruh perkembangan teknologi informasi. Konvergensi menurut Fidler (2003) merupakan bagian dari mediamorfosis, yakni proses media melakukan transformasi sebagai dampak dari hubungan kait-mengkait antara kebutuhan, persaingan, politik, 
berbagai inovasi sosial dan teknologi. Dalam rangka adaptasi tersebut, jurnalis dituntut untuk memiliki kemampuan multikeahlian (Dupagne \& Garrison, 2006).

Gordon membagi konvergensi media ke dalam lima dimensi / level, yakni ownership convergence, tactical convergence, struktural convergence, information gathering convergence dan story telling convergence.

Redaksi sebagai jantung media mengeluarkan kebijakan yang menjadi pengejawantahan konvergensi. Kebijakan itulah yang disebut kebijakan redaksional. Sebuah sikap politik media dalam memandang suatu permasalahan juga aturan keredaksian dan kewartawanan. Tentu politik redaksional akan berdampak pada setiap orang yang ada di dalamnya.

Redaksi media merespon konvergensi dengan meningkatkan kemampuannya dalam menyajikan berita. Peningkatan kemampuan tersebut akan berdampak terhadap pola kerja wartawan sebagai ujung tombak pencarian berita. Kebijakan redaksional diperlukan untuk melakukan perubahan pola kerja agar dampak yang dihasilkan juga menjadi positif.

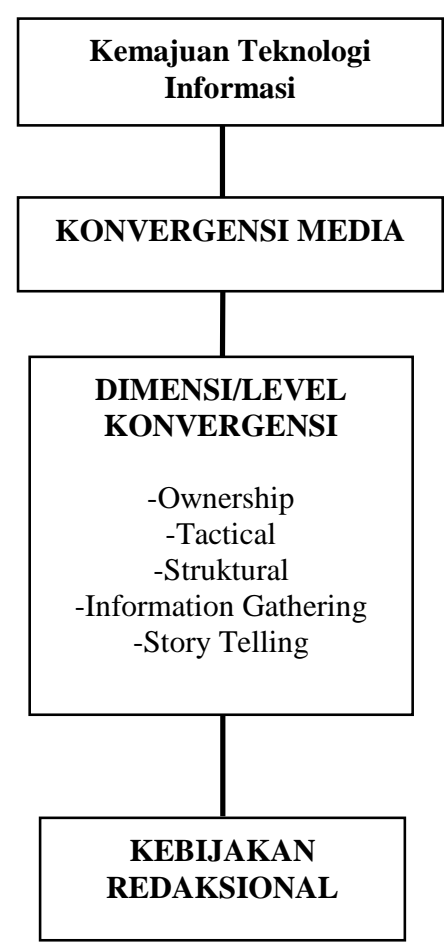




\section{HASIL DAN PEMBAHASAN}

a. Ekspansi Perusahaan

Perubahan menjadi kata kunci yang wajib dipegang oleh industri media. Begitu juga dengan Jawa Pos yang yakin bahwa perubahan menjadi sesuatu yang wajib dihadapi, bukan dihindari. Sejak awal koran yang lahir di Surabaya ini mengambil tagline "Selalu Ada yang Baru". Bukan semata tulisan yang ditempel di bawah logo Jawa Pos, namun menjadi prinsip yang diimplementasikan ke dalam produknya. Perubahan bukan hanya dipicu oleh kondisi sosial ekonomi budaya masyarakat, namun juga yang utama adalah perkembangan pesat teknologi informasi. Media yang memegang kata kunci tersebut akan selalu melihat perkembangan zaman dan beradaptasi untuk bertahan. Bagi media cetak, perubahan bukan hanya direspon dengan perbaikan konten sehingga mampu bersaing dengan sesama cetak. Tetapi juga bersiap untuk menghadapi perubahan dengan banyaknya jenis pesaing dari elektronik dan digital.

Jawa Pos sebagai media konvensional menyadari harus menghadapi pesaing yang datang dari berbagai bentuk media. Sebagaimana surat kabar lainnya, Jawa Pos tidak memiliki kemampuan melawan atau bersaing dengan citra televisi yang menarik secara visual dan media baru memiliki kekuatan dalam hal kecepatan. Maka untuk mengantisipasi perkembangan Jawa Pos menganggap perlu revolusi dalam industri media melalui konvergensi. Media elektronik dan digital yang semula dianggap sebagai musuh baru koran harus dirangkul dan dibuat berjalan seiring bersama. Sebab bagi Jawa Pos, melakukan transformasi ke media digital adalah sebuah keniscayaan.

Jawa Pos juga merespon dengan cepat. Pada awalnya Jawa Pos hidup dibawah PT Jawa Pos sebagai perusahaan yang membawahi seluruh penerbitan yang ada dalam satu grupnya. Jawa Pos sebagai perusahaan operasional juga berperan sebagai holding company. Kemudian pada 2009 Dahlan Iskan menyadari perkembangan industri media 
kian cepat menuju ke arah konvergensi. Sehingga perlu menyusun strategi baru di bidang manajemen perusahaan. Akhirnya dibuat satu holding company yang berada di struktur paling atas diberi nama PT Jawa Pos Holding. Dibawahnya terdapat perusahaanperusahaan diantaranya PT Temprina Media Grafika yang bergerak di bidang percetakan dan PT Adi Prima sebagai perusahaan produksi kertas. Termasuk PT Jawa Pos Koran. PT Jawa Pos Koran sendiri juga masih memiliki anak perusahaan yaitu PT. Jawa Pos Radar dan PT Jawa Pos Group Multimedia.

“Dulu sebelum 2009 itu Jawa Pos sebagai perusahaan operasional, ya Jawa Pos sebagai holding. Sejak tahun 2009, setelah Pak Dahlan jadi Dirut PLN, yang holding kita naikin ke atas. Kita bikinkan perusahaan-perusahaan yang salah satunya sekarang ini saya bekerja, namanya Jawa Pos Koran. Di Jawa Pos Koran ini punya beberapa anak perusahaan lagi, punya saham di perusahaan-perusahaan,namanya PT. Jawa Pos Radar, " (SOF, 9 Nopember 2017).

Dahlan Iskan saat itu memiliki pemikiran bahwa bisnis media yang dikelola tidak bisa dikerjakan dalam satu perusahaan besar dengan menajemen seadanya. Dia menggunakan prinsip usaha 'jangan meletakkan telur dalam satu keranjang'. Artinya, unit usaha yang ada di group Jawa Pos harus dibuatkan legalitas masing-masing. Legalitas yang berupa perusahaan itulah yang diibaratkan sebagai keranjang. Maka munculah Jawa Pos Group Multimedia, sebuah holding company yang menaungi seluruh perusahaan-perusahaan di Jawa Pos Group. Antara lain jawapos.com, JPNN, PT Adi Prima (pabrik kertas), Temprima (percetakan).

"Jadi disini saling mengakuisisi. Saking banyaknya dan semua dibuatkan PT. Ini semua untuk kaki-kaki, agar kalau berjalan tidak pincang. Dulu sebelum dibikin perusahaan sendiri anatara jawapos.com dengan Jawa Pos jadi satu. Waktu itu jawapos.com cuma kompartemen," (SOF, November 2017).

Jawa Pos Group Multimedia sebagai holding company terus melakukan ekspansi di berbagai jenis usaha. Ekspansi yang dilakukan akan berpengaruh terhadap 
keberlangsungan perusahaan secara umum serta sebagai penunjang dalam menghadapi konvergensi media. Bahkan jika sewaktu-waktu industri media diharuskan melakukan konvergensi secara sempurna, Jawa Pos siap melakukannya. Perusahaan-perusahaan yang didirikan oleh manajemen cukup efektif untuk menopang kebutuhan konvergensi media.

"Jawa Pos masih jauh dari kata konvergensi. Tapi bahwa jika memang harus melakukan, Jawa Pos sudah siap. Kan tinggal nge klik saja. Karena infrastrukturnya sudah ada," (DOS, 9 Nopember 2017).

Kesiapan infrastruktur untuk konvergensi diakui menjadi pondasi yang kuat. Jawa Pos juga siap untuk melakukan konvergensi dan berkompetisi dengan pasar.

\section{b. Promosi Silang}

Setelah Jawa Pso melakukan ekspansi usaha, setiap perusahaan dibawah naungan Jawa Pos Group Multimedia tidak bekerja secara sendiri-sendiri. Masingmasing perusahaan memililiki platform yang khas dan unik. Namun manajemen memberlakukan kebijakan agar setiap platform saling mendukung.

Salah satu contohnya adalah Jawa Pos Group yang memiliki delapan jenis majalah dan tabloid yang terbit mingguan. Yakni Nyata, Posmo, Koki, Ototrend, Agrobis, Komputek, Nurani, dan Main Basket. Seluruh majalah dan tabloid itu dikelola oleh manajemen yang terpisah dari Jawa Pos Koran namun saling bersinergi. Misalnya adanya promosi di halaman Jawa Pos saat buletin terbit dengan tema-tema khusus. Selain majalah dan tabloid, Jawa Pos Group juga memiliki 39 stasiun televisi lokal di berbagai daerah di Indonesia. Penggunaan internet dan handphone dengan segala turunannya yang semakin masif dan digitalisasi media radio dan televisi memudahkan khalayak mengakses informasi dari manapun. 
"Di Jawa Pos koran ini punya beberapa anak-anak perusahaan lagi, namanya Jawa Pos Radar. Kalau sekilas itu kayak Jawa Pos persis cuma dalemnya diganti gitu. Selain itu ada namanya Jawa Pos multimedia, termasuk jawapos.com dan jpnn. Semua konten bisa didistribusikan ke seluruh anak perusahaan tersebut," (SOF, 9 November 2017).

Kerjasama pendistribusian konten selama ini memang sudah dilakukan ke seluruh media di Jawa Pos Group. Dilihat dari intensitasnya, pendistribusian konten paling kerap dilakukan dari Jawa Pos ke jawapos.com.

"Kerjasamanya kita mengindeks. Misalnya saya bikin liputan khusus di Metropolis(salah satu halaman di Jawa Pos - pen), nah sore itu saya ngomong ke redaktur dot kom kalau besok mau bikin laporan khusus. Ini foto-fotonya, ini grafisnya, ini teasernya. Silahkan dimuat di jawapos.com," (DOS, 9 November 2017).

Dengan promosi silang yang dilakukan Jawa Pos dengan berbagai perusahaan lain yang berada dalam satu group menjadikan Jawa Pos Group Multimedia memiliki akar yang kuat.

\section{c. Menciptakan SDM Serba Bisa}

Perombakan manajemen di Jawa Pos dilakukan berdasarkan kebutuhan perusahaan. Seluruh sumber daya manusia (SDM) yang ada di perusahaan harus mampu melaksanakan tugas sesuai dengan tugas pokok dan fungsinya. Perubahan struktur secara tidak langsung membuat orang-orang di dalamnya menyesuaikan diri. Dalam kenyataannya ada karyawan yang harus berpindah divisi karena menyesuaikan kebutuhan perusahaan. Di divisi baru tersebut, seorang karyawan harus mampu melaksanakan tugas dengan baik. Meskipun bidang yang digeluti sangat jauh berbeda dengan latar belakangnya. Sebagai contoh, seorang wartawan Jawa Pos koran harus berpindah ke jawapos.com. Ada pula wartawan Jawa Pos yang juga harus melakukan peliputan untuk jawapos.com. 
"Waktu awal kita nggak minta wartawan. Jadi waktu awal itu ya wartawan cetak diminta untuk menulis di jawapos.com. Akhirnya setelah ada setahun kita bikinkan manajemen lebih serius. Kita bikinkan perusahaan sendiri, punya GM (General Manajer) sendiri, wartawan sendiri sampai sekarang," (SOF, 9 November 2017).

Wartawan cetak yang juga ditugaskan untuk mengisi jawapos.com tidak diberikan pembekalan khusus. Karena pola penulisan keduanya tidak jauh berbeda. Saat itu format penulisan di jawapos.com sama dengan format koran yakni panjang dan lengkap. Secara otodidak wartawan cetak memiliki multiskill. Mereka dapat melakukan kerja untuk produk cetak, online, bahkan ketika peliputan khusus juga digunakan untuk video.

“Ada yang liputan ekspedisi Cheng Ho, itu konvergensi itu. Buat online, pake video dan sebagainya. Aku dulu waktu liputan pilpres di Amerika aku juga sambil video untuk teve. Ya nggak ada yang ngajarin. On cam itu gimana yasudah begini aja. Banyak wartawan disana yang pakai seperti itu, memang wartawan secara global begitu," (SOF, 9 November 2017).

Perubahan pola kerja tersebut secara tidak langsung menjadikan karyawan Jawa Pos siap melaksanakan tugas sesuai dengan visi dan misi perusahaan yang baru.

"Di tingkat manajemen juga mengalami perubahan. Ada pimpinan yang sebelumnya di Redaksi, kemudian diminta untuk mengelola event. Ada pula bagian iklan koran dipindah ke televisi dan lain-lain. Mereka harus bisa menyesuaikan diri," (DOS, 9 Nopember 2017).

Dari tiga hal yang telah dilakukan Jawa Pos tersebut menunjukkan jika Jawa Pos sebagai sebuah perusahaan media telah melalui empat level konvergensi. 


\section{DAFTAR PUSTAKA}

Aryanti, Dian Metha, Konvergensi Parsial di Media (Studi Kasus di Media Grup). Pascasarjana Universitas Indonesia, 2011.

Baran, Stanly J \& Davis, Dennis K, Teori Komunikasi Massa: Dasar, Pergolakan, dan Masa Depan (Edisi Kelima). Jakarta: Penerbi Salemba Humanika, 2010.

Crisell, A, An Introductory History of British Broadcasting. London: Routledge, 2002.

Dawyer, T, Media Convergence. Berkshire: McGraw-Hill, 2010.

Djudjuk Juyoto, Jurnalistik Praktis, Sarana Penggerak Lapangan Kerja Raksasa. Jogjakarta: Nur Cahya, 1985.

Djuroto, Totok, Manajemen Penerbitan Pers. Bandung: Remaja Rosdakarya, 2005.

Dupagne, M., \& Garrison, B, The Meaning and Influence of Convergence. Aqualitative Case Study of NewsroomWork at the Tampa News Center. New York: Oxford University Press, 2009.

Fidler, Roger, Mediamorfosis. Yogyakarta: Bentang Budaya, 2003.

Fisher, H. A, Developing Media Managers for Convergence. New York: Oxford University Press, 2007.

Franklin, B., Hamer, M., Hanna, M., Kinsey., \& Richardson, J.E. Key Concepts in Journalism Studies. London: Sage Publication, 2005.

Gordon, R. The Meanings and Implications of Convergence. Lanham: Rowman \& Littlefield Publisher. Inc, 2003.

Grant A. E. \& Wilkinson, J.S., Understanding Media Convergence: The State of The Field. NY: Oxford University Press, 2009.

Jenkins, H, Convergence Culture. New York: New York University Press, 2006.

Kriyantono, Rachmat, Teknik Praktis Riset Komunikasi. Jakarta: Kencana Prenada Media Group, 2008.

Kurniawan Junaedi, Ensiklopedi Pers Indonesia.Jakarta: PT.Gramedia Pustaka Utama, 1991.

Lukman Ali, et.al., Kamus Besar Bahasa Indonesia. Jakarta: Balai Pustaka, 1994. 
Maskun Iskandar, Ensiklopedia Nasional Indonesia. Jakarta: PT. Cipta Abdi Pustaka, 1990.

McChesney, Robert W, Global Media, Neoliberalisme, and Imperialism. Monthly Review, Vol. 52, 2001.

McQuail D, Teori Komunikasi Massa Suatu Pengantar. Jakarta: Salemba Humanika, 2005.

Moleong, L. J, Metodologi Penelitian Kualitatif. Bandung: PT Remaja Rosdakarya, 2005.

Nabi, R. L., \& Oliver, M. B., Media Processes and Effects. London: SAGE Publication, 2009.

Noor, Henry Faizal, Ekonomi Media. Jakarta: Rajawali Pers, 2010.

Pawito, Penelitian Komunikasi Kualitatif. Yogyakarta: LkiS Yogyakarta, 2007.

Pacey, Arnold, The Culture of Technology ( $9^{\text {th }}$ Editions).Massachusetts: The MIT Press Cambridge, 2000.

Pape, S., \& Featherstone, S, Newspaper Journalism. London: Sage Publications, 2005.

Pavlik, J.V, Journalism and the New Media. New York: Columbia University Press, 2001.

Quinn. S., \& Filak, V.F, Convergent Journalism. An Introduction. Oxford: Focal Press, 2005.

Quinn, Stephen, Convergence: The Journal Research Into New Media Technologies. London: Sage Publication Inc. Vol. 10, 2004.

Senor, J, The Newsroom of Tomorrow: Two Innovation Strategy For Getting There. Pamplona: Innovation International Media Consulting Group, 2010.

Septiawan Santana K, Jurnalisme Kontemporer. Jakarta: Yayasan Obor Indonesia, 2005.

Soria, C, The Core Business of a Media Company is to Maximize the Quality of Its Newsroom. Pamplona: Innovation International Media Consulting Group, 2008.

Straubhaar, J. \& La Rose, R, Media Now: Understanding Media, Culture, and Technology. $5^{\text {th }}$ Ed. Update. CA: Thomson, 2008. 
Straubhaar, J; La Rose, Robert \& Davenport, Lucinda, Media Now: Understanding Media Culture, and Technology. $6^{\text {th }}$ Ed. USA: Wadsworth, 2009.

Sudirman Tebba, Jurnalistik Baru. Jakarta: Kalam Indonesia, 2005.

Sugiya, Aritasius, Strategi Transformasi Konvergensi Media: Studi Kasus Grand Strategy Harian Kompas. Jakarta: Universitas Indonesia, 2012.

Supadiyanto, Implikasi Teknologi Digital dan Internet (Paperless Newspaper) Pada Industri Media Cetak di Indonesia. dppm.uii.ac.id/dokumen/seminar/2013/G.Supadiyanto.pdf, 2013.

Suprapto, Tommy. Politik Redaksi Berita: Menguak Latar Belakang Teks Berita Media. Jakarta: Pustaka Kaiswaran, 2010.

Syahriar, A, Kajian Konvergensi Teknologi Informasi dan Komunikasi. Jakarta: Badan Pengkajian dan Penerapan Teknologi, 2007.

Trivino, Alfredi dalam Asmono Wikan, Digitalisasi mengubah Ritual Jurnalisme, Media Directory, 2011.

WAN-IFRA, World Press Trends 2010, halaman 629-636.

Yin, Robert K, Studi Kasus (Desain dan Metode). Jakarta: PT Raja Grafindo Persada, 1997.

Yoffie, B, Competing in the Age of Digital Convergence. Harvard Business School Press, 1997.

Wikan, Asmono, Tahun-Tahun yang Menantang bagi Media Cetak. Media Directory, 2010.

--------------Inovasi Produk Tiada Henti, dalam Media Directory, 2011.

Jurnal Ilmiah SCRIPTURA, Vol. 3, No 1, Januari 2009: 69-84. 